\title{
New method of predicting surge pressure apply to horizontal well based on casson flow*
}

\author{
Yuxue Sun, Qiming Li ${ }^{\#}$, Jingyuan Zhao \\ Petroleum Engineering Department; Northeast Petroleum University; Daqing, China; ${ }^{\#}$ Corresponding Author: userlqm@126.com
}

Received 14 September 2010; revised 20 October 2010; accepted 23 October 2010.

\begin{abstract}
In order to predict the surge pressure caused in the horizontal well drilling process, a new simple and applicable method has been established. It is based on the general theory of hydrostatic drilling fluid mechanics, and specifically described the flowing physical model towards surge pressure in horizontal well annulus, taking the effect of string eccentricity on the flowing law of drilling fluid into consideration. According to the constitutive equation of casson-mode under one-dimensional steady flow and the equations of annular flow rate under different drill string working conditions, this paper introduced the flow rate computation models of axial laminar flow in eccentric annulus apply to horizontal well, of which the numerical model was calculated by the program called Mathematica, ultimately, a new model for surge pressure prediction towards each interval in horizontal well was put forward. Application examples indicated that it can solve questions easily and precisely, which presents important meaning of guidance to the safety control while horizontal well drilling.
\end{abstract}

Keywords: Surge Pressure; Horizontal Well; Eccentric Annulus; Casson-Mode

\section{INTRODUCTION}

While pipe or casing string pulling and running in the well, the drilling fluid adhesive to the string moves with it and the motion of the string has to get over the viscous force of fluid at the same time, which causes an additional pressure on the borehole face, named Surge Pressure, an important effect factor related to the formation stability [1-3]. Traditional computation model of surge

"Project of Natural Science Foundation of Heilongjiang Province, China: The Study on Membrane Drilling Fluid Technology pressure is mostly applicable to vertical well $[4,5]$. The model of horizontal well has also been studied recently, however, it involves mathematic theory of comparative complexity which leads to the inconvenient computation and low efficiency of application, as a result, the predicting model apply to horizontal well still has more space to develop [6-9].

This paper presents a method of predicting surge pressure applicable to horizontal well based on casson flow, because casson-mode is more precise to describe the rheological behaviour of drilling fluid with high shearing rate inside the pipe or around the bit nozzle $[10,11]$. This new method conjugates the flow rate computation models of axial laminar flow in eccentric annulus and uses Mathematica software conducting the numerical calculation to simplify the computational procedure, which can also help predict the surge pressure caused in vertical well and directional well.

\section{PHYSICAL FLOWING MODEL IN HORIZONTAL WELL BORE}

This model neglects the compressibility of the fluid and well bore, it does consider the complexities of the non-Newtonian flow of drilling fluid and choose casson-mode as the rheological behavior of the fluid. It is assumed that the drilling fluid is under isothermal laminar flow in eccentric annulus with fixed-length in the axis, and at the same time it considers the motion parameters of every spatial point in flow field to be time-invariant, which can simplify the calculation with negligible impact on the predicting result. This is because the previous predicting results under the hypothesis of traditional models are a little more conservative, that means the predicting magnitude is bigger than normal, but this prerequisite of steady flow can make an effect of correction [12-15].

In the intervals of deviated hole and horizontal hole, action of gravity makes the string diverge from the borehole central axis, and the annulus between the string and borehole tends to be eccentric, which will influence 
the flowing pattern of the drilling fluid, that means the assumption of concentric annulus generally accepted in drilling annular hydraulics computation will not be applicable any more [16-19].

Figure 1 and Figure 2 present respectively the physical flowing model in eccentric annulus and the simplified model of flowing section in eccentric annulus. The borehole radius is $D_{h}$, the outside radius of running string is $d_{o}$, the inside radius of running string is $d_{i}$, the hole deviation angle is $\alpha$, the average annular flowing velocity of drilling fluid is $\bar{v}$, the velocity of running string is $v_{p}$, the eccentric arm between the axis of the string and that of the borehole is e, and the clearance, at any circumferential angle $\theta$, between the outside surface of the string and the inside borehole wall is $\mathrm{h}$,

$$
\mathrm{h}=\sqrt{D_{h}^{2}-e^{2} \sin ^{2} \theta}-d_{o}+e \cos \theta
$$

We choose a micro hexahedron unit at any circumferential angle $\theta$ in the annulus along the direction paralleled with the flowing. In Figure 3, $\tau$ is the shear stress between fluid layers, $\mathrm{L}$ is the length of fluid along the flowing direction, and $\Delta \mathrm{p}$ is the pressure drop within that length L. In a steady-flow model, because the external forces on the micro unit should balance we can get this [20]:

$$
\frac{\partial p}{\partial z}+\frac{\partial \tau}{\partial y}=0
$$

When the shape of flowing section along the flowing direction is considered invariable and the fluid is incompressible, we get this:

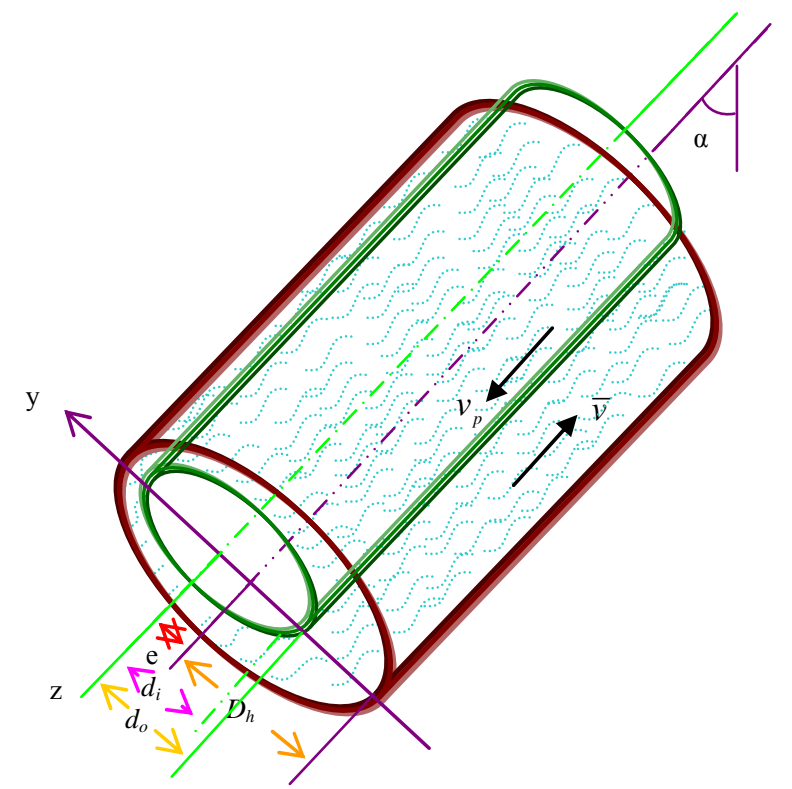

Figure 1. Physical flowing model in eccentric annulus.

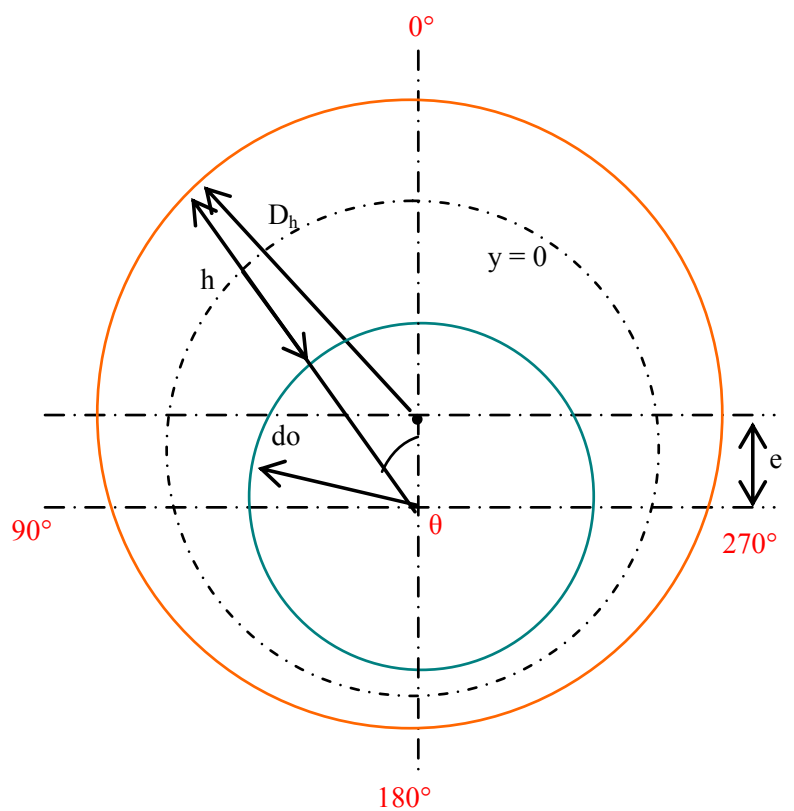

Figure 2. Simplified model of flowing section in eccentric annulus.

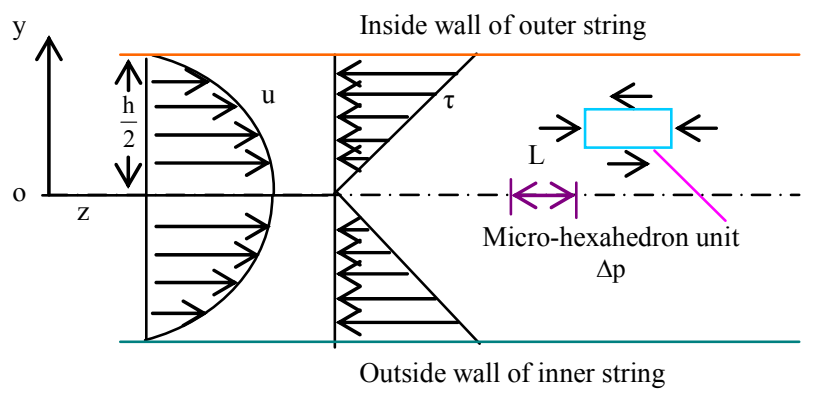

Figure 3. Force analysis of annulus fluid.

$$
-\frac{\partial \mathrm{p}}{\partial \mathrm{z}}=\frac{\Delta p}{L}
$$

So the surge pressure in the borehole annulus at the hole deviation angle $\alpha$ is:

$$
P_{s}=\frac{\Delta p}{L} \cos \alpha
$$

\section{COMPUTATIONAL MODEL ESTABLISHING}

\subsection{Flow Rate Computation in Eccentric Annulus}

According to the coordinate system showed in Figure 3, casson flow's rheological equation is:

$$
\tau=\left[\eta_{\infty}^{1 / 2}\left(-\frac{d u}{d y}\right)^{1 / 2}+\tau_{\mathrm{c}}^{1 / 2}\right]^{2}
$$


Combine Eq.4 with Eq.1:

$$
\frac{\mathrm{d} u}{d y}=-\left(\frac{\Delta \mathrm{p}}{\eta_{\infty} L} y+\frac{\tau_{c}}{\eta_{\infty}}\right)+\frac{2}{\eta_{\infty}} \sqrt{\frac{\Delta p \tau_{c}}{L} y}
$$

Integrate the above equation, then the point velocity of fluid at any circumferential angle $\theta$ under different values of $\mathrm{y}$ is:

$$
\begin{aligned}
\mathrm{u}(\theta, y) & =\frac{\Delta p}{2 L \eta_{\infty}}\left[\left(\frac{h}{2}\right)^{2}-y^{2}\right]+\frac{\tau_{c}}{\eta_{\infty}}\left(\frac{h}{2}-y\right) \\
& -\frac{4}{3 \eta_{\infty}}\left(\frac{\Delta p}{L}\right)^{1 / 2} \tau_{c}^{1 / 2}\left[\left(\frac{h}{2}\right)^{3 / 2}-y^{3 / 2}\right]
\end{aligned}
$$

So the axial laminar flow rate model of casson flow in eccentric annulus is:

$$
\begin{aligned}
\mathrm{Q} & =\int_{0}^{2 \pi} \mathrm{dQ}=\int_{0}^{2 \pi} v(\theta) d s \\
& =\int_{0}^{2 \pi}\left(2 d_{o}+h\right) \int_{0}^{h / 2} u(\theta, y) d y d \theta
\end{aligned}
$$

\subsection{Flow Rate Analysis under Practical Working Conditions}

Four types of working conditions are usually applied on site and they are plugging string with pump opened, plugging string with pump closed, opening string with pump opened and opening string with pump closed. There is much in common between the conditions of plugging string with pump opened and opening string with pump opened under which fluids are expelled from mud pump inside the string and then influence the average flowing velocity in the well, therefore, these two conditions can be merged into one [21-23].

We consider that workstring is rigid and drilling fluid is steady-flow, and take into account the annulus flowing velocity changes aroused by the adhesion effect of drilling fluid. According to the relationship between the displacement of drilling fluid expelled by the running string in unit time and the flowrate in annulus, we can establish the equilibrium equation to get the average flowing velocity in annulus under three different working conditions respectively:

1) Plugging string with pump closed:

$$
\bar{v}=1.5\left[\frac{d_{o}^{2}}{D_{h}^{2}-d_{o}^{2}}+K_{c}\right] \bar{v}_{p}
$$

2) Opening string with pump closed:

$$
\bar{v}=1.5\left[\frac{d_{o}^{2}-d_{i}^{2}}{D_{h}^{2}-d_{o}^{2}+d_{i}^{2}}+K_{c}\right] \bar{v}_{p}
$$

3) Plugging or opening string with pump opened:

$$
\bar{v}=1.5\left[\frac{d_{o}^{2}}{D_{h}^{2}-d_{o}^{2}}+K_{c}\right] \bar{v}_{p}+\frac{Q_{p}}{\pi\left(D_{h}^{2}-d_{o}^{2}\right)}
$$

In the equations above: $Q_{p}$ is the output volume of mud pump, $K_{c}$ is adhesion coefficient, dimensionless. Refer to the experienced data and theoretical relationship plate of adhesion coefficient and annular ratio(ratio of string diameter) based on power law flow and casson flow, $K_{c}$ is generally ranged from 0.4 to 0.5 , and when the annulus ratio $d_{0} / D_{h}$ is more deviated from 1 , the magnitude of $K_{c}$ is more close to 0.4 .

According to the average annular velocity $\bar{v}$ under different working conditions and the annular section area $\mathrm{s}, \mathrm{s}=\pi\left(D_{h}^{2}-d_{o}^{2}\right)$, we can work out the annular flowrate $\mathrm{Q}_{t}, \mathrm{Q}_{t}=\bar{v} s$, corresponding to different working conditions:

$$
\begin{gathered}
\mathrm{Q}_{t}=4.71\left[K_{c} D_{h}^{2}+\left(1-K_{\mathrm{c}}\right) d_{o}^{2}\right] \bar{v}_{p} \\
\mathrm{Q}_{t}=4.71\left[\frac{\left(d_{o}^{2}-d_{i}^{2}\right)\left(D_{h}^{2}-d_{o}^{2}\right)}{D_{h}^{2}-d_{o}^{2}+d_{i}^{2}}+K_{c}\left(D_{h}^{2}-d_{o}^{2}\right)\right] \bar{v}_{p} \\
\left.\mathrm{Q}_{t}=4.71\left[K_{c} D_{h}^{2}+\left(1-K_{\mathrm{c}}\right) d_{o}^{2}\right]\right] v_{p}+\mathrm{Q}_{p}
\end{gathered}
$$

\subsection{Computation Model of Surge Pressure}

After programming on Mathematica software to compute Eq.7 and containing different value theory and elliptic integral, we finally got the mathematical model to compute the flowrate of axial laminar flow of casson flow in eccentric annulus (Eq.14), here we only give the equation under the working condition of plugging string with pump closed as an example, and the other two conditions should be computed in the same way.

$$
\begin{aligned}
& \mathrm{Q}=\frac{\Delta \mathrm{p}}{L} \frac{2}{3 \eta_{\infty}}\left[A \pi+B \varsigma+e^{2} d_{o} \varsigma-\frac{8}{3} d_{o} \xi+\frac{2 e}{3} \xi\right] \\
& +\sqrt{\frac{\Delta p}{L}} \frac{2 \sqrt{\tau_{c}}}{5 \eta_{\infty}}\left[\mathrm{B} \pi+C \varsigma+\frac{8}{3} \xi\right]+\frac{\tau_{c}}{\eta_{\infty}}\left[\mathrm{B} \pi+C \varsigma+\frac{8}{3} \xi\right]
\end{aligned}
$$

There into:

$$
\begin{aligned}
& \mathrm{A}=\frac{1}{2}\left(D_{h}^{4}-e^{3} d_{o}-d_{o}^{4}\right)+D_{h}^{2} e^{2}+D_{h}^{2.64} e^{2.64} d_{o}^{-2.2} \\
& \mathrm{~B}=d_{o}^{3}-D_{h}^{2} d_{o}-e^{3}-D_{h}^{2.64} e^{2.64} d_{o}^{-3.03} \\
& C=D_{h}^{2}-d_{o}^{2}-e^{2} \\
& \varsigma=D_{h} E\left(\frac{e^{2}}{D_{h}^{2}}\right)+\sqrt{D_{h}^{2}-e^{2}} E\left(\frac{e^{2}}{e^{2}-D_{h}^{2}}\right) \\
& \xi=D_{h}\left(\left(D_{h}^{2}+e^{2}\right) K\left(\frac{e^{2}}{D_{h}^{2}}\right)+\left(e^{2}-D_{h}^{2}\right) K\left(\frac{e^{2}}{D_{h}^{2}}\right)\right)
\end{aligned}
$$


$\mathrm{K}(\mathrm{m})$ is complete elliptic integral of the first kind and $\mathrm{E}(\mathrm{m})$ is complete elliptic integral of the second kind, of which values can be solved by programming on Mathematica software.

Combine the worked out annulus flowrate corresponding to specific working condition (Eqs.11-13) with Eq.14, so the pressure gradient $\frac{\Delta \mathrm{p}}{L}$ can be calculated, then put it into Eq.3, and the surge pressure gradient at the hole deviation angle $\alpha$ in the well bore annulus is got.

Until now, based on the above analysis and calculation, we can calculate the surge pressure gradient $P_{i}$ of each interval in horizontal well, even including the most complicated well structure as showed in Figure 4.

The calculation equations of surge pressure for different well intervals and the total surge pressure expression at any well depth in horizontal well are presented as follow.

- Vertical interval, hole deviation angle $\alpha$ is $0^{\circ}$, $P_{i}=\left.P_{s}\right|_{\alpha=0}$

- Deviated interval (angle gaining interval and angle dropping interval), hole deviation angle $\alpha$ changes from $\alpha_{1}$ to $\alpha_{2}, \quad P_{i}=\int_{\alpha_{1}}^{\alpha_{2}} P_{s} d_{\alpha}$

- Hold angle interval, hole deviation angle $\alpha$ is invariant, $P_{i}=P_{\mathrm{s}}$

- Horizontal interval, hole deviation angle $\alpha$ is $90^{\circ}$, $P_{i}=\left.P_{s}\right|_{\alpha=90}$

Thereinto, "i $i$ " indicates the sequence number of the interval location in horizontal well, $P_{i}$ is the corresponding annulus surge pressure when the sequence number is $i, L_{i}$ is the corresponding well depth of that specific interval, so the magnitude of surge pressure at any well depth $(i=n)$ is: $P=\sum_{i=1}^{n} P_{i} L_{i}$.

\section{SURGE PRESSURE PREDICTION WITH ACTUAL EXAMPLE}

There is a certain horizontal well filled with drilling fluid which presents Casson-mode: $\tau_{\mathrm{c}}=1.51(\mathrm{~Pa}), \eta_{\infty}=$ 15.5 (mPa.s). The $\Phi 244.48$ (mm) casing pipe of which inside diameter is $222.5(\mathrm{~mm})$ starts to build angle at a vertical depth of $600(\mathrm{~m})$ and the initial hole deviation angle $\alpha_{1}=8^{\circ}$. The $\Phi 127(\mathrm{~mm})$ drilling pipe of which inside diameter is $82(\mathrm{~mm})$ runs at the speed of $1(\mathrm{~m} / \mathrm{s})$ and starts to hold angle at a vertical depth of 2204.82 (m), where the hole deviation angle $\alpha_{2}=84^{\circ}$ and the well depth is $2306.13(\mathrm{~m})$. Supposed the working condition is plugging string with pump closed, try to calculate the annular surge pressure at the pipe shoe (in the drilling pipe annulus) and determine the corresponding addition mud density.

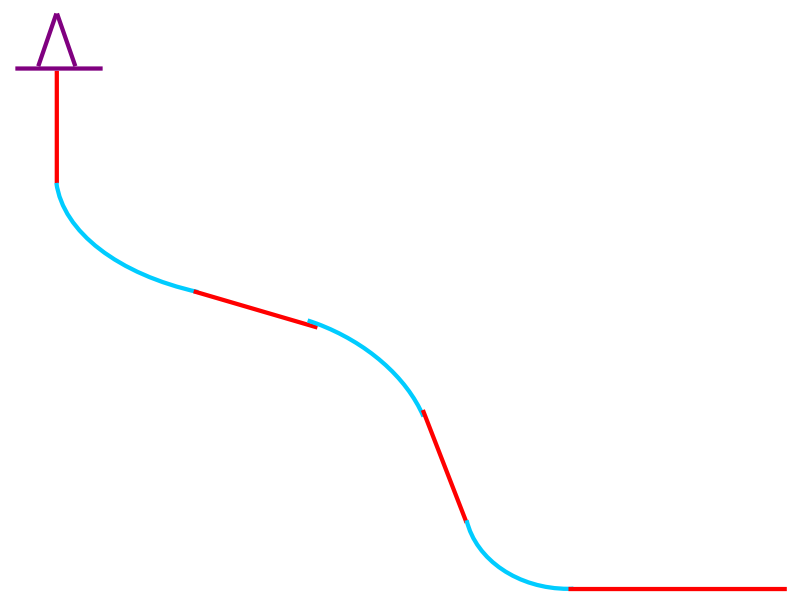

Figure 4. Horizontal wellbore structure.

Some known calculation parameters are mentioned above, they are: $\tau_{\mathrm{c}}=1.51(\mathrm{~Pa}), \eta_{\infty}=15.5(\mathrm{mPa} . \mathrm{s}), 2 D_{h}=$ $222.5(\mathrm{~mm}), 2 d_{o}=127(\mathrm{~mm}), 2 d_{i}=82(\mathrm{~mm}), \bar{v}_{p}=1$ $(\mathrm{m} / \mathrm{s}), \alpha_{1}=8^{\circ}, \alpha_{2}=84^{\circ}$ and some length parameters: $L_{1}=$ $600(\mathrm{~m}), L_{2}=2204.82(\mathrm{~m})-600(\mathrm{~m})=1604.82(\mathrm{~m})$. Then we can conduct the calculation as follow.

Firstly, the degree of eccentricity is generally taken as 0.5 , so the eccentricity arm $e=0.5 * 0.5 *(\Phi 244.48-\Phi$ $127)=0.0239(\mathrm{~m})$. Then we substituted $D_{h}\{0.11125$ $(\mathrm{m})\}, d_{o}\{0.0635(\mathrm{~m})\}$, e $\{0.0239(\mathrm{~m})\}$ into the corresponding expression followed Eq.14 to get the value of A, $\mathrm{B}$ and $\mathrm{C}$ in Eq.14: $\mathrm{A}=0.000110297, \mathrm{~B}=-0.000937975$, $\mathrm{C}=0.007979025$.

Secondly, using Mathematica program to compute the elliptic integral $E\left(\frac{e^{2}}{D_{h}^{2}}\right), E\left(\frac{e^{2}}{e^{2}-D_{h}^{2}}\right)$ and $K\left(\frac{e^{2}}{D_{h}^{2}}\right)$. After substituting and computing we got: $\mathrm{E}(0.0295)=$ $1.55914, \mathrm{E}(-0.0304)=1.58267, \mathrm{~K}(0.0295)=1.58258$, $\mathrm{K}(-0.0304)=1.55905$, so $\varsigma=0.34691, \xi=0.00019$.

Thirdly, annular ratio $\{127(\mathrm{~mm}) / 222.5(\mathrm{~mm})=0.57\}$ is comparatively small, so we considered the adhesion coefficient $\mathrm{Kc}=0.4$ and we substituted the numerical values of $K_{c}(0.4), D_{h}(0.11125), d_{o}(0.0635), \bar{v}_{p}(1)$ in Eq.9, then we got the annular flow rate under the condition of plugging string with pump closed: $\mathrm{Q}_{t}=$ $4.71 *\left(0.4 * 0.11125^{2}+0.6 * 0.0635^{2}\right) * 1=0.034\left(\mathrm{~m}^{3} / \mathrm{s}\right)$.

After calculating the annular flow rate $\mathrm{Q}_{t}$ and parameters such as $\mathrm{A}, \mathrm{B}, \mathrm{C}, \varsigma$ and $\xi$, we substituted them into Eq.14, so we can got the pressure gradient $\frac{\Delta \mathrm{p}}{L}=$ $0.1917859(\mathrm{kPa} / \mathrm{m})$. According to what is presented in Eq.3, the annular surge pressure Ps at hole deviation angle $\alpha$ is: $P s=0.1917859 * \cos \alpha$.

At vertical interval within the depth of $L_{1}=600(\mathrm{~m})$, its surge pressure:

$\mathrm{P} 1=P_{1} * L_{1}=\left.P_{s}\right|_{\alpha=0} * L_{1}=0.1917859(\mathrm{kPa} / \mathrm{m}) * 600$ 
$(\mathrm{m})=115.072(\mathrm{kPa})$.

At angle gaining interval within the depth of $L_{2}=$ $1604.82(\mathrm{~m})$, its surge pressure:

$$
\begin{aligned}
& \mathrm{P} 2=P_{2} * L_{2}=\int_{\alpha_{1}}^{\alpha_{2}} P_{s} d_{\alpha} * L_{2}=0.1917859(\mathrm{kPa} / \mathrm{m}) * \\
& \left(\sin 84^{\circ}-\sin 8^{\circ}\right)^{*} 1604.82(\mathrm{~m})=263.254(\mathrm{kPa}) \text {. } \\
& \text { The total annular surge pressure value at the pipe shoe } \\
& \text { is: } \\
& \mathrm{P}=\mathrm{P} 1+\mathrm{P} 2=115.072(\mathrm{kPa})+263.254(\mathrm{kPa})= \\
& 378.326(\mathrm{kPa}) \text {. } \\
& \text { The corresponding addition mud density is: } \\
& \rho=\mathrm{P} / \mathrm{gH}=378.326(\mathrm{kPa}) /\left\{9.8(\mathrm{~N} / \mathrm{kg})^{*} 2204.82(\mathrm{~m})\right\}= \\
& 0.0175\left(\mathrm{~g} / \mathrm{cm}^{3}\right) .
\end{aligned}
$$

\section{CONCLUSIONS}

Based on the rheological mode of Casson flow, the flow rate computation models of axial laminar flow in eccentric annulus apply to horizontal well were successfully established. Finally, we developed a new model of predicting surge pressure imposed on different intervals in horizontal well, of which the numerical model could be calculated by the program called Mathematica conveniently. And the magnitude of the predicting surge pressure provided a criterion in determining the addition mud density.

After calculating the actual example using this new model and comparing with traditional predicting method, it is obvious that this new model can be computed easily by the field engineers. Across the steps of derivation of this new model, we concluded that it can calculate flexibly, it provides a method of predicting surge pressures in vertical well and directional well after being simplified. And this new model can also direct the secure production on location through predicting surge pressures under different working conditions of drill string.

\section{ACKNOWLEDGEMENTS}

We would like to thank the drilling engineers Shurui Zhang and Guobin Li from Daqing Oil Field for their supports to the field test and operations

\section{REFERENCES}

[1] Burkhardt, J.A. (1961) Wellbore pressure surges produced by pipe movement. Journal of Petroleum Technology, 13, 595-605.

[2] Rasmussen, O.S. and Sangesland, S. (2007) Evaluation of MPD methods for compensation of surge-and-swab pressures in floating drilling operations (IADC/SPE108346). IADC/SPE Managed Pressure Drilling \& Underbalanced Operations, Galveston, Texas, USA, 2007, $1-11$.

[3] Wang, W. and Gong, J. (2006) Controlling surge due to accidental shutoff fast closing valve at terminal station of an oil pipeline (SPE-100914). International Oil \& Gas Conference and Exhibition, Beijing, China, 2006, 1-7.

[4] Tao, Q., Xia, H., Peng, M. and Li, B. (2006) Research on surge pressure of casing running in high-temperature high-pressure oil well. Fault-Block Oil \& Gas Field, 13, 58-60.

[5] Fan, H. and Liu, X. (1990) Analysis on surge pressure caused by mud viscosity in vertical well. Journal of the University of Petroleum, 14, 8-14.

[6] Fan, H., Chu, Y. and Liu, X. (1995) Predition for wellbore dynamic surge pressure while tripping a drillpipe. Journal of the University of Petroleum, 19, 37-41.

[7] Bizanti, M.S., Mitchell, R.F. and Leturno, R.E. (1991) Are improved surge models needed (SPE-22057). Unpublished.

[8] Wang, H. and Liu, X. (1994) Study on steady surge pressure of casson fluid in concentric annulus of directional wells. Drilling Fluid and Completion Fluid. 11, $35-44$.

[9] Zhong, B., Shi, T., Fu, J. and Miao, S. (1999) Model for computing surge and swab pressures in slim end horizontal holes. Journal of Southwest Petroleum Institute, 21, 52-55.

[10] Wang, Z. and Tang, S. (1982) Casson rheological model in drilling fluid mechanics. International Petroleum Exhibition and Technical Symposium, Beijing, China, 1982, 397-435.

[11] Sun, W., Chen, J. and Li, Z. (1986) Comparison of rheological models in high shear rate range and experimental relationship between penetration rate and high shear viscosities. International Meeting on Petroleum Engineering, Beijing, China, 1986, 267-277.

[12] Manohar, L. (1983) Surge and swab modelling for dynamic pressures and safe trip velocities. IDAC/SPE Drilling Conference, New Orleans, Louisiana, 1983, 427-433.

[13] Wang, H., Su, Y. and Liu, X. (1998) Numerical analysis of steady surge pressure of power law fluid in eccentric annuli. Acta Petrolei Sinica, 19, 104-109.

[14] Wang, L., Yang, H., Xu, Q., Lan, X. and Shen, Q. (2008) An analytic model for stable-state flow in horizontal wellbore drilled by stable foam. Natural Gas Industry, 28, 90-92.

[15] Meliande, P., Elson, A.N., João, P.D. and André L.L.M. (2008) Surge pressure analysis for Bijupira and Salema water injection system (OTC 19365). Offshore Technology Conference, Houston, Texas, USA, 2008, 1-8.

[16] Wang, H. and Liu, X. (1996) Solution of surge pressure of power-law fluid in the deviated sections of directional well. Journal of the University of Petroleum, 20, 29-33.

[17] Zhong, B., Zhou, K. and Xie, Q. (1995) Theoretical study of steady-state surge and swab pressure in eccentricc annulus. Journal of Southwest-China Petroleum Institute, 17, 38-45.

[18] Wang, H., Liu, X. and Dong J (1996) Approximate solution of stable fluctuation pressure of newtonian fluid in eccentric annular. Oil Drilling \& Production Technology, 18.

[19] Wagner, R.R., Halal, A.S. and Goodman, M.A. (1993) Surge field tests highlight dynamic fluid response (SPE/IADC-25771). SPE/IADC Drilling Conference, Amsterdam, Netherlands, 1993, 883-892. 
[20] Chukwu, Godwin A (1995) A practical approach for predicting casing running speed from couette flow of non-newtonian power-law fluids(29638). SPE Western Regional Meeting, Bakersfield, California, 1995, 263268.

[21] Yang, X. (2003) Study on preventing and plugging lost circulation technique in Daqing Yingtai area. Master's Paper of Northeast Petroleum University, unpublished.

[22] Samuel, G.R., Sunthankar, A., Colpin, G.M., Bern, P. and
Flynn, T. (2003) Field validation of transient swab-surge response with real-time downhole pressure data (SPE-85109). SPE Drilling \& Completion, 18, 280-283.

[23] Scott, T., LoGiudice, M., Gaspard, G. and Vidal, D. (2010) Multiple-opening diverter tool reduces formation surge pressure and increases running speeds for casing and liners (SPE-135178). SPE Annual Technical Conference and Exhibition. 